\title{
Artikel
}

\section{Kindvriendelijke rechtspraak - wat valt te verwachten voor het jeugdstrafrecht?}

\author{
Mr. E.A.A. (Ellen) van Kalveen*
}

\section{Inleiding}

Kindvriendelijke rechtspraak 'child friendly justice' is een term die steeds vaker gebruikt wordt. Het is niet alleen in Nederland maar ook internationaal een thema. Het Internationaal Verdrag inzake de Rechten van het Kind ('IVRK') en dan in het bijzonder het recht op participatie, is de basis van deze internationale en nationale ontwikkeling. In Nederland lijkt de laatste jaren de aandacht voor kindvriendelijke rechtspraak vooral gericht op het jeugdbeschermingsrecht en op familiezaken. In deze bijdrage zal ik nagaan welke praktische aspecten in het jeugdstrafrecht aandacht behoeven in het licht van kindvriendelijke rechtspraak. Het gaat dan om de rol van de advocaat, procesbekwaamheid, diverse randvoorwaarden, communicatie ter zitting en via het vonnis, overschrijding van de redelijke termijn ('undue delay') en status delicten als spijbelen.

\section{Ontstaan van kindvriendelijke rechtspraak}

De basis van kindvriendelijke rechtspraak is gelegen in artikel 12 van het IVRK. ${ }^{1}$ Dat artikel behelst het recht van het kind om te worden gehoord en het recht dat er

\footnotetext{
Ellen van Kalveen is senior rechter en voorzitter van de expertgroep jeugdrechter. Dit artikel is op persoonlijke titel geschreven.

1. T. Liefaard \& S. Rap, 'Hoezo kindvriendelijk? Over "child-friendly justice" ter bevordering van effectieve participatie van kinderen in juridische procedures en besluitvorming', FJR 2018/41, par. 2.
}

met de mening van het kind rekening wordt gehouden. In de rechtspraak van het Europese Hof voor de Rechten van de Mens ('EHRM') is het recht op effectieve participatie door kinderen erkend. Vanuit de Raad van Europa zijn de Guidelines on Child-friendly justice ('Guidelines') opgesteld die richting geven aan de lidstaten om procedures kindvriendelijk in te richten. ${ }^{2}$ Omdat het EHRM in uitspraken ook naar de Guidelines verwijst, worden deze Guidelines onderdeel van het geldende recht. Naast deze ontwikkeling heeft het VN-Kinderrechtencomité in 2019 een nieuw General Comment gepubliceerd over het jeugdstrafrecht. ${ }^{3}$ Ook de Europese Unie heeft de bescherming van minderjarigen in het strafrecht hoog in het vaandel en heeft een aantal richtlijnen tot stand gebracht waarin dit tot uiting komt. ${ }^{4}$

\section{Het belang van participatie}

Het centrale thema bij kindvriendelijke rechtspraak - ongeacht welk rechtsgebied - is participatie. In een groot antal internationale onderzoeken komt naar voren dat participatie in juridische procedures die hen betreffen voor kinderen positieve effecten heeft. ${ }^{5}$ Ook voor

2. rm.coe.int/CoERMPublicCommonSearchServices/DisplayDCTMContent?documentld $=090000168045 \mathrm{f5a9}$.

3. General comment No. 24 (2019) on children's rights in the child justice system, te raadplegen via: tbinternet.ohchr.org/_layouts/15/ treatybodyexternal/Download.aspx?symbolno $=\mathrm{CRC} / \mathrm{C} / \mathrm{GC} /$ 24\&Lang=en

4. Richtlijn (EU) $2016 / 800$ van 11 mei 2016 betreffende procedurele waarborgen voor kinderen die verdacht of beklaagde zijn in een strafprocedure.

5. T. Liefaard \& S. Rap, 'Hoezo kindvriendelijk? Over "child-friendly justice" ter bevordering van effectieve participatie van kinderen in juridische procedures en besluitvorming', FJR 2018/41, par. 3. 
kinderen geldt dat de procedurele rechtvaardigheid van belang is. Het horen en betrekken van kinderen, zodat zij daadwerkelijk begrijpen wat er gebeurt, moet dus niet alleen een formaliteit zijn. Kinderen hebben ondersteuning van volwassenen nodig bij deze participatie. Bij kindvriendelijk jeugdstrafrecht zijn dat de professionals, de officier van justitie, de advocaat en de rechter. Een kindvriendelijke procedure is niet een mal die op ieder kind moet worden toegepast, maar behelst het handelen met respect voor de leeftijd en de ontwikkeling van het kind en de kwetsbaarheden. ${ }^{6}$ Daarnaast kan participatie door het kind zelf voor de professional ook een bron van informatie zijn.

\section{Ontwikkelingen in het jeugdbeschermingsrecht en het familierecht}

Omdat op dit moment op deze rechtsgebieden de belangrijkste ontwikkelingen lijken plaats te vinden, zal ik deze kort aanstippen.

Essentieel verschil tussen jeugdstrafrecht enerzijds en het jeugdbeschermingsrecht en het familierecht anderzijds, is de formele procespositie van het kind. Kort gezegd - en alle nuancering achterwege latend - is het kind in het jeugdrecht en het familierecht procesonbekwaam, terwijl het kind in het jeugdstrafrecht een eigen formele procespositie heeft. In het jeugdbeschermingsrecht en het familierecht heeft het kind in procedures die het aangaan met name het recht te worden gehoord, tijdens het kindgesprek. Binnen de rechtspraak is veel aandacht voor het vormgeven aan het kindgesprek, zie daarvoor bijvoorbeeld de professionele standaard van de gerechtshoven. ${ }^{7}$

Een in het oog springende ontwikkeling is het ontstaan van kindvriendelijke uitspraken. ${ }^{8} \mathrm{Op}$ die manier wordt de beslissing van de rechter op een voor het kind toegankelijkere manier verwoord. Op deze wijze kan dan ook een terugkoppeling plaatsvinden van het kindgesprek.

Om de drempel voor het gesprek te verlagen zijn er in diverse rechtbanken speciale ruimtes voor het kindgesprek; meer een spreekkamer dan een zittingszaal.

De leeftijd waarop kinderen standaard een uitnodiging krijgen voor een kindgesprek is ook onderwerp van discussie. Bij de Rechtbanken Den Haag en Amsterdam worden kinderen onder de 12 jaar in een aantal type zaken uitgenodigd voor een kindgesprek. In Amsterdam

\section{Guidelines par. 54.}

7. www.rechtspraak.nl/SiteCollectionDocuments/professionele-standaardkindgesprekken.pdf\#search=standaard.

8. Bijv.: Rechtbank Midden-Nederland 22 maart 2017, ECLI:NL:RBMNE: 2017:1541, en Rechtbank Oost-Brabant 17 februari 2020, ECLI:NL: RBOBR:2020:1087. gaat het om kinderen tussen de 8 en 12 jaar die uitgenodigd worden in zaken over uithuisplaatsing, hoofdverblijf, omgang en verhuizing. In de teruggeleidingszaken rondom internationale kinderontvoering, die geconcentreerd zijn bij de Rechtbank Den Haag, ontvangen kinderen ouder dan 6 jaar een uitnodiging voor een kindgesprek. De 'Staatscommissie Herijking Ouderschap' adviseert een groot aantal leeftijdgrenzen te verlagen en de positie van de minderjarige te versterken. ${ }^{9}$

Het lang verwachte WODC-onderzoek naar de procespositie van de minderjarige in het familie- en jeugdrecht is bij het schrijven van dit artikel nog niet gepubliceerd. Een van de te beantwoorden vragen is of kinderen een formele procespositie moeten krijgen in het jeugdbeschermingsrecht en in het familierecht, dus of ze als volwaardige partij een procedure kunnen starten of daaraan kunnen deelnemen.

Al met al een groot aantal ontwikkelingen ten aanzien van kindvriendelijke rechtspraak bij het beschermingsrecht en het familierecht, die nog lang niet afgerond zijn.

\section{General Comment 20 over adolescentie}

Wat gebeurt er nu in het jeugdstrafrecht met betrekking tot kindvriendelijke rechtspraak? Zoals al aangegeven zijn, behalve het IVRK, ook de Guidelines, de General Comment No. 24 over het jeugdstrafrecht en de EUrichtlijn 2016/800 van belang voor het jeugdstrafrecht. Daarnaast is ook General Comment No. 20 over de adolescentie relevant. ${ }^{10}$ Adolescentie wordt beschreven als de transitie van jeugd naar volwassenheid. Deze General Comment richt zich op de leeftijdsgroep van 10 tot 18 jaar. Voor de gemiddelde Nederlandse jeugdrechtbeoefenaar is dat mogelijk een verrassende definitie van adolescentie, want die denkt sneller aan de jongmeerderjarigen van 18 tot 23 jaar. Het adolescentenstrafrecht maakt het immers mogelijk jeugdstrafrecht op die laatstgenoemde leeftijdsgroep toe te passen. Het VN-kinderrechtencomité benadrukt dat het belangrijk is de adolescentie als een positieve ontwikkelingsfase te waarderen en betreurt de wijdverbreide negatieve karakterisering van de adolescentie. Ook benadrukt het VN-kinderrechtencomité dat de toegenomen kennis omtrent de hersenontwikkeling duidelijk maakt dat bescherming nodig blijft. $^{11}$ Door nog niet voldoende ontwikkeling van

9. www.rijksoverheid.nl/documenten/rapporten/2016/12/07/rapportvan-de-staatsommissie-herijking-ouderschap-kind-en-ouders-inde-21ste-eeuw.

10. General Comment No. 20 (2016) on the implementation of the right of the child during adolescene, te raadplegen in het Nederlands en het Engels via: www.kinderrechten.nl/general-comment-nr-20-overadolescentie/.

11. E.P. Schmidt, 'De implementatie van kinderrechten tijdens de adolescentie: General Comment No. 20 en de positie van adolescenten in het Nederlandse strafrecht, TvJr 2019/2, p. 55. 
bepaalde belangrijke hersenfuncties komt bepaald risicogedrag vooral bij deze leeftijdsgroep voor. Dat risicogedrag brengt dan weer contacten met politie en justitie met zich mee. Het risico is dat het kind binnen het strafrecht alleen wordt gezien als een gevaarlijk kind, in plaats van ook een kind in gevaar. Participatie van het kind en investeren in kindvriendelijke rechtspraak heeft misschien niet altijd prioriteit, maar verdient het wel.

\section{Leeftijdsgrenzen}

Participeren gaat ook over de positie van het kind in procedures. Anders dan in het jeugdbeschermingsrecht en het familierecht heeft de minderjarige verdachte een eigen positie, hij ${ }^{12}$ is bekwaam in rechte op te treden. Zijn positie is in veel opzichten vergelijkbaar met die van een volwassen verdachte, maar dan met extra bescherming. Die bescherming is gelegen in een verplichte advocaat die een verdachte onder de 16 jaar kan vertegenwoordigen, de bijzondere positie van de ouders in de procedure en het plaatsvinden van de zitting achter gesloten deuren. Waar de discussie in het jeugdbeschermingsrecht en het familierecht gaat over het toekennen van extra mogelijkheden (verlagen leeftijd horen en toekennen eigen rechtsingang), gaat de discussie in het jeugdstrafrecht meer over het verhogen van de leeftijdsgrens. In het advies van de Raad voor de Strafrechtstoepassing en Jeugdbescherming (RSJ) van 2017 wordt beargumenteerd dat de leeftijdsgrens van strafrechtelijke aansprakelijkheid verhoogd zou moeten worden, omdat een kind pas strafrechtelijk vervolgd kan worden als het competent en capabel is om de consequenties van het eigen handelen te zien. Omdat de meeste kinderen pas vanaf hun veertiende begrijpen wat er gebeurt in een strafrechtelijk proces, is deze leeftijd de gewenste minimumleeftijd. ${ }^{13}$ In zijn 'Kamerbrief aanpak Jeugdcriminaliteit' van 28 juni 2019, geeft de Minister van Justitie en Veiligheid in reactie op het advies van de RSJ aan dat de leeftijdsgrens van 12 jaar zal worden behouden, omdat hij de mogelijkheid om bij ernstige delicten strafrechtelijk te kunnen ingrijpen wil behouden en omdat deze leeftijdsgrens in overeenstemming is met het IVRK. ${ }^{14}$ In de op 18 september 2019 gepubliceerde nieuwe General Comment No. 24 over het jeugdstrafrecht worden Staten echter opgeroepen de minimumleeftijd te verhogen naar 14 jaar, mede gelet op de bevindingen op het terrein van de hersenfuncties. ${ }^{15}$ In het RSJ-advies worden een aantal zorgen geuit of de huidige jeugdhulpverlening in de praktijk voldoende in staat is om een effectieve aanpak te bieden voor jongeren die zorg behoeven. ${ }^{16}$ Over het functioneren van de

12. Waar staat hij kan ook zij gelezen worden.

13. RSJ (2017), Advies verhoging strafrechtelijke leeftijd in context, p. 27, te raadplegen via: www.rsj.nl/documenten/rapporten/2017/12/20/ advies-verhoging-strafrechtelijke-leeftijd.

14. www.rijksoverheid.nl/documenten/kamerstukken/2019/06/28/tkaanpak-jeugdcriminaliteit.

15. General Comment No. 24 (2019), par. 20 e.v.

16. RSJ (2017), Advies verhoging strafrechtelijke leeftijd in context, p. 24. gedwongen jeugdhulpverlening zijn de zorgen zo groot geworden, dat in november 2019 de Minister van Volksgezondheid, Welzijn en Sport en de Minister voor Rechtsbescherming in een brief aan de Tweede Kamer constateren dat de uitvoering van de jeugdbescherming onder grote druk staat, zoals blijkt uit de bij die brief gevoegde rapportages van de inspecties. ${ }^{17}$ Op korte termijn lijkt verhoging van de minimumleeftijd daarom niet voor de hand te liggen. Wil van een eerlijk proces gesproken kunnen worden, dan rust er op de betrokken professionals de extra complexe taak om zo'n jonge verdachte in staat te stellen zijn rechten uit te oefenen.

\section{Kindvriendelijke omgeving, taal en procedure}

In de Guidelines is een onderdeel gewijd aan onder andere een kindvriendelijke omgeving en kindvriendelijke taal en procedure. ${ }^{18} \mathrm{Op}$ deze punten zal ik daarom verder ingaan. Hoe staat het er voor in Nederland en wat kan er beter?

\subsection{Het gebouw}

Omdat een rechtbank vrij imponerend kan zijn, is in de Guidelines ook aangegeven dat kinderen bekend zouden moeten zijn met de inrichting van de rechtbank en met de personen die aanwezig zullen zijn. Daar is een rol weggelegd voor zowel de rechtbank als de advocatuur. Behulpzaam daarbij zijn de beelden als een soort streetview van veel rechtbank- en gerechtshoflocaties. ${ }^{19}$ Voor het kind dat zich in voorlopige hechtenis bevindt op het moment van de zitting, is de hoofdingang niet de toegang tot de zittingszaal. Hij bevindt zich in het cellencomplex van de rechtbank, met naast hem de volwassen gedetineerde verdachten. Dat is geen kindvriendelijke, vertrouwenwekkende omgeving. In sommige gerechtsgebouwen is vlak bij dit cellencomplex een kindvriendelijke ophoudruimte. Deze ruimtes zijn ontwikkeld voor kinderen die in een gesloten jeugdhulpinstelling verblijven op civielrechtelijke titel. Het is niet standaard dat minderjarige verdachten in deze ruimte worden geplaatst. Het lijkt echter een eenvoudige manier om de omgeving waar de minderjarige verdachte in de rechtbank verblijft minder kindonvriendelijk te maken.

\subsection{De zittingszaal}

In meerdere artikelen wordt gemeld, dat in een informelere setting de communicatie tussen rechter en kind beter verloopt. ${ }^{20}$ In het explanatory memorandum wordt

17. www.tweedekamer.nl/kamerstukken/brieven_regering/detail? id=2019Z21588\&did=2019D44885.

18. Guidelines, par. 54 e.v.

19. www.rechtspraak.nl/Organisatie-en-contact/Organisatie/Rechtbanken/ Rechtbank-Overijssel en www.rechtspraak.nl/Organisatie-en-contact/ Organisatie/Gerechtshoven/Gerechtshof-Amsterdam.

20. S. Rap \& I. Weijers, De jeugdstrafzitting: een pedagogisch perspectief. De communicatie tussen jeugdrechter en jeugdige verdachte, Raad voor de rechtspraak, Den Haag: Sdu Uitgevers 2011, p. 147, te raadplegen via: www.rechtspraak.nl/SiteCollectionDocuments/De- 
aangegeven dat, hoewel bestaande gebouwen niet makkelijk aangepast kunnen worden, er toch mogelijkheden zijn om binnen bestaande gebouwen meer kindvriendelijk te handelen. ${ }^{21}$ De positie van het kind in de zittingszaal, naast zijn advocaat of juist helemaal alleen, staand of zittend, maakt ook veel uit. Het al dan niet dragen van toga's heeft twee kanten. Aan de ene kant kan het dragen van toga's intimiderend zijn, aan de andere kant maakt zo'n kledingstuk - net als bijvoorbeeld het politie-uniform - de functie duidelijk. Het laat ook zien dat het kind serieus genomen wordt door een rechter. Dit onderdeel van het explanatory memorandum sluit af met de samenvatting dat de omgeving tamelijk formeel kan zijn, maar dat het gedrag van de professionals minder formeel zou moeten zijn en in ieder geval kindvriendelijk. ${ }^{22}$ Voor de Nederlandse situatie betekent dit, dat er met deze blik naar de zittingszalen gekeken kan worden. Zittingszalen waarbij de verdachte en advocaat niet naast elkaar kunnen zitten, zouden enigszins aangepast kunnen worden. De allergrootste zittingszaal van een gerechtsgebouw is minder geschikt voor een enkelvoudige kinderzitting, die kan dus beter niet daar plaatsvinden.

\subsection{Ongewenste ontmoetingen}

Kindvriendelijke organisatie van een procedure betekent dat stress tussen ouders en kind in de wachtruimte van de rechtbank zoveel mogelijk voorkomen moet worden. Als een kind een ouder jaren niet heeft gezien, is de context van een strafzitting niet het moment om kind en ouder elkaar weer te laten ontmoeten. Datzelfde geldt als de relatie tussen een of beide ouders en/of het kind gespannen is. In het jeugdbeschermingsrecht en in het familierecht is nadrukkelijk aandacht gevraagd voor de ongemakkelijke situaties die in de wachtruimte van de rechtbank kunnen ontstaan. ${ }^{23}$ Allereerst is alertheid nodig om deze situaties te detecteren. Oplossingen kunnen dan gelegen zijn in aparte wachtruimtes en/of het niet tegelijk horen (voor zover de wet dat toelaat).

\subsection{De taal op de zitting}

Centraal in de procedure staat de zitting. Tijdens de Nederlandse jeugdstrafzitting is in het algemeen ruimte voor het kind om te participeren. Dit komt naar voren in een uitgebreid onderzoek uit 2011 van jeugdstrafrechtzittingen in diverse Europese landen door Rap en Weijers. ${ }^{24}$ Aandachtspunt bleek het gebruik van jargon.

jeugdstrafzitting-een-pedagogisch-perspectief.pdf; A. van TeijlingenPover, 'De gerechtelijke procedure in jeugd- en familiezaken door de ogen van kinderen', Trema 2019/02.

21. Het explanatory memorandum is gevoegd achter de Guidelines, beide te vinden via: rm.coe.int/CoERMPublicCommonSearchServices/ DisplayDCTMContent?documentld=090000168045f5a9.

22. Guidelines, explanatory memorandum nr. 123.

23. A. van Teijlingen-Pover, 'De gerechtelijke procedure in jeugd- en familiezaken door de ogen van kinderen', Trema 2019/02.

24. Te lezen in: K.G.M. van Dijk-Fleewoord-Bird 'De onzichtbare handicap van het jeugdstrafrecht, De taalvaardigheden van minderjarige verdachten en de implicaties voor het jeugdstrafrecht, DD 2017/71, par. 4.2; S. Rap \& I. Weijers, De jeugdstrafzitting: een pedagogisch perspectief. De communicatie tussen jeugdrechter en jeugdige verdachte, Raad voor de rechtspraak, Den Haag: Sdu Uitgevers 2011, p. 95.
In de opleiding en training van rechters wordt hier, zeker de laatste jaren, veel aandacht aan besteed. Daarnaast is het voor professionals handig om alternatieven voor het jargon tot hun beschikking hebben. De op internet beschikbare 'Moeilijke Woordenlijst Strafrechtketen' kan inspiratie bieden. ${ }^{25}$ Het bieden van duidelijkheid en structuur vergroot het begrip van de zitting. ${ }^{26}$ In dat kader valt de hand-out op, die als bijlage is gevoegd bij de handreiking voor de advocatuur over het bijstaan van jeugdigen en ouders met een licht verstandelijke beperking. ${ }^{27}$ Deze hand-out geeft een zittingsagenda en zou door de kinderrechter gebruikt kunnen worden op zitting. In een moderne digitale zaal zou deze agenda getoond kunnen worden op een scherm en in andere zittingszalen zou dit document op de tafel bij de verdachte gelegd kunnen worden. Dit zou zich goed lenen voor een experiment.

\subsection{De lengte van de zitting}

De bevindingen over de Nederlandse situatie in het onderzoek van Rap en Weijers uit 2011 zijn in grote mate gebaseerd op jeugdstrafzittingen van alleensprekende kinderrechters. ${ }^{28}$ Mijn persoonlijke indruk is dat de behandelduur van jeugdstrafzaken, met name op de meervoudige kamer, steeds langer is geworden. Naar de juistheid van deze indruk of naar eventuele oorzaken is geen onderzoek gedaan. Duidelijk is wel, dat het zeer de vraag is of de concentratieboog van een kind lang genoeg is om alert te blijven bij een ellenlange zitting van een of meerdere dagen. In de Guidelines wordt hier ook aandacht voor gevraagd. ${ }^{29}$ De zitting moet aangepast worden aan het tempo en de aandachtsspanne van een kind. Regelmatig zouden onderbrekingen gepland moeten worden en de zittingen zouden niet te lang moeten duren. Het is daarom van belang dat alle betrokken professionals zich allereerst bewust zijn van de noodzaak om zittingen niet te lang te laten duren. Dat vereist van deze professionals, dat ze een goede afweging maken van wat er besproken dient te worden en hoe uitgebreid. In het algemeen kan namelijk gezegd worden dat bij de vormgeving van een zitting keuzes gemaakt kunnen worden, afhankelijk van het soort strafzaak. Aan het ene eind van het spectrum staat de jeugdstrafzitting achter gesloten deuren zonder een spreekgerechtigde en benadeelde partij, en aan het andere eind staat een landelijk geruchtmakende strafzaak tegen een meerderjarige verdachte in het openbaar met meerdere spreekgerechtigden en benadeelde partijen. In het laatste geval brengt de openbaarheid mee dat het publiek en de pers uitgebreid worden geinformeerd over de inhoud van het

25. www.basistoolstrafrechtketen.nl/moeilijke-woordenlijst/.

26. S. Rap \& I. Weijers, De jeugdstrafzitting: een pedagogisch perspectief. De communicatie tussen jeugdrechter en jeugdige verdachte, Raad voor de rechtspraak, Den Haag: Sdu Uitgevers 2011, p. 142.

27. www.hsleiden.nl/binaries/content/assets/hsl/lectoraten/lvb-enjeugdcriminaliteit/handreiking-Ivb-advocatuur-jeugd-def-091219.pdf. Deze handleiding is ook voor anderen dan advocaten relevant.

28. S. Rap \& I. Weijers, De jeugdstrafzitting: een pedagogisch perspectief. De communicatie tussen jeugdrechter en jeugdige verdachte, Raad voor de rechtspraak, Den Haag: Sdu Uitgevers 2011, p. 95.

29. Guidelines, par. 61. 
strafdossier. In het eerste geval is er geen publiek dat geïnformeerd behoeft te worden en kennen alle anwezigen het complete dossier. Dit is duidelijk een onderwerp dat nadere aandacht behoeft, niet alleen bij de rechters, maar ook bij advocatuur en officieren van justitie.

\subsection{De taal van de uitspraak}

$\mathrm{Na}$ de behandeling van de zaak volgt de uitspraak, hetzij mondeling, hetzij schriftelijk. De Guidelines maken ook duidelijk dat de beslissing goed gemotiveerd moet zijn en aan kinderen uitgelegd moet worden op een voor hen begrijpelijke manier. ${ }^{30}$ In de Guidelines rust deze taak vooral op de advocaat. ${ }^{31}$ Binnen het commune strafrecht wordt in het arrondissement Rotterdam met een nieuwe opzet geëxperimenteerd. Dit experiment past in de rechtspraakbrede aandacht voor Klare taal (het streven om makkelijk leesbare uitspraken te schrijven). Het Rotterdamse experiment heeft veel andacht getrokken. ${ }^{32}$ Minder aandacht is er geweest voor de jeugdstrafvonnissen in kindvriendelijke taal. ${ }^{33}$ Het verschil tussen bijvoorbeeld: 'als verdachte die werkstraf niet, of niet goed doet, dan moet verdachte 40 dagen de jeugdgevangenis' en 'indien niet naar behoren verricht te vervangen door 40 dagen jeugddetentie' is vrij groot. Op dit punt is dus de strafrechtspraak kindvriendelijker te maken.

\section{De opleiding van de professionals}

Zoals al eerder aangegeven is het aan de volwassenen en in de strafprocedure aan de advocaat, de officier van justitie en de rechter, om het mogelijk te maken dat een kindvriendelijke procedure plaatsvindt. Daarom is in de Guidelines opgenomen dat alle professionals die met en voor kinderen werken een interdisciplinaire training krijgen over de rechten en behoeften van kinderen in de verschillende leeftijdsgroepen. Daarnaast zouden alle professionals die in direct contact staan met kinderen getraind moeten zijn in communicatie met kinderen. ${ }^{34}$ Uit de EU-richtlijn 2016/800 blijkt ook het belang van opleiding van deze professionals om de rechten van minderjarige verdachten te waarborgen. ${ }^{35}$ De specialisatie 'jeugd' bij de rechterlijke macht, het parket van de officier van justitie en de advocatuur staat regelmatig door verschillende omstandigheden onder druk. De invulling van het specialisme is aan de organisaties zelf overgelaten. Bij het parket van de officier van justitie

30. Guidelines, par. 49

31. Guidelines, par. 75

32. S. Dunk, 'Rotterdamse strafrechters schrijven heldere vonnissen', Advocatenblad, 2019/7, p. 49

33. Rechtbank Den Haag 20 september 2018, ECLI:NL:RBDHA: 2018:11607; Rechtbank Zeeland-West-Brabant 20 juni 2019, ECLI:NL:RBZWB:2019:2700; Rechtbank Zeeland-West-Brabant 7 december 2018, ECLI:NL:RBZWB:2019:6815.

34. Guidelines, par. 14 en 15 .

35. Art. 20 Richtlijn (EU) 2016/800 van 11 mei 2016 betreffende procedurele waarborgen voor kinderen die verdacht of beklaagde zijn in een strafprocedure. dreigt het door de ontwikkelingen rondom ZSM (Zorgvuldig, Snel en op Maat) weer onder te sneeuwen door de aandacht an generalistisch werken. ${ }^{36}$ Binnen de rechterlijke macht heeft de vergrote aandacht voor de samenhang tussen de jeugdbeschermingszaken en de familierechtelijke zaken het risico, dat de samenhang tussen het jeugdstrafrecht en de jeugdbeschermingszaken uit het oog wordt verloren. Daarnaast kampen beide organisaties met personeelstekorten, waardoor keuzes ten aanzien van personeelsinzet soms uit nood zijn geboren.

De rol van de advocaat is essentieel, omdat een van de belangrijkste pijlers om tot kindvriendelijke rechtspraak te komen het geven van passende informatie en advies over het aan het kind gemaakte strafrechtelijke verwijt, en over de gang van zaken rond het strafproces is. ${ }^{37}$ Vanuit de jeugdrechtadvocatuur zijn er veel zorgen over de financiering van hun werk, waardoor het de vraag is of aan deze essentiële voorwaarde voor kindvriendelijke rechtspraak altijd voldaan kan worden. ${ }^{38}$

\section{Snelheid}

Het uitgangspunt dat jeugdstrafzaken snel moeten worden behandeld wordt algemeen gedeeld. Snelheid is dan ook een onderdeel van kindvriendelijke rechtspraak. Zowel de Guidelines als de EU-richtlijn 2016/800 benadrukken dit. ${ }^{39}$ In de Kamerbrief 'Aanpak jeugdcriminaliteit' wordt opgemerkt dat de in 2001 opgestelde normen voor doorlooptijden, de zogenoemde Kalsbeeknormen, in slechts iets meer dan de helft van alle zaken worden gehaald. Er wordt gewerkt aan het versnellen van de doorlooptijden. ${ }^{40} \mathrm{Al}$ met al blijven de doorlooptijden echter een punt van zorg in een tijd waar de rechtspraak kampt met achterstanden en een tekort aan rechters. ${ }^{41}$

\section{Afsluitende opmerkingen}

In deze bijdrage is nagegaan welke praktische aspecten aandacht behoeven in het licht van kindvriendelijke rechtspraak in het Nederlandse jeugdstrafrecht. Kind-

36. J. uit Beijerse \& C.L. van der Vis, 'Een voorzet voor modernisering van het jeugdstrafrecht in lijn met het IVRK en met oog voor de knelpunten in de praktijk', Tijdschrift modernisering strafvordering 2019/1.

37. Guidelines, par. 1

38. Zie onder meer: Redactie Advocatenblad, 'Dekker gaat praten met jeugdrechtadvocaten', Advocatenblad, 5 juli 2019.

39. Art. 13 Richtlijn (EU) 2016/800 van 11 mei 2016 betreffende procedurele waarborgen voor kinderen die verdacht of beklaagde zijn in een strafprocedure; Guidelines, par. 50.

40. Punt 3.1 Kamerbrief: www.rijksoverheid.nl/documenten/kamerstuk ken/2019/06/28/tk-aanpak-jeugdcriminaliteit.

41. www.rechtspraak.nl/Organisatie-en-contact/Organisatie/Raad-voorde-rechtspraak/Nieuws/Paginas/Rechtspraak-duur-rechtszaak-moetkorter.aspx 
vriendelijke rechtspraak is toegankelijk, houdt rekening met de leeftijd, behoeften en rechten van het kind.

Het jeugdstrafrecht heeft zeker wat te verwachten van een kindvriendelijke rechtspraak. De ontwikkelingen in het jeugdbeschermingsrecht en in het familierecht zijn ook relevant voor het jeugdstrafrecht en kunnen ter inspiratie dienen. Het gaat dan onder andere om aandacht voor een kindvriendelijke omgeving en kindvriendelijke taal. Daarnaast is gebleken dat kindvriendelijke rechtspraak kortere doorlooptijden en professionals met specialistische kennis vereist.

Maar het belangrijkste is dat kinderen in procedures met respect worden behandeld en dat rekening wordt gehouden met hun leeftijd en ontwikkeling.

\section{Boy}

De roman speelt in de Verenigde Staten in de jaren twintig van de vorige eeuw. Het verhaal wordt verteld door de journalist William Stevens. Boy is een doofstomme jongen die 'in een korte broek' bij Amy Faye is aan komen lopen en door haar opgevangen. Hij doet geen vlieg kwaad maar wordt op enig moment aangetroffen in een kast in de slaapkamer van de filmster Polly Todd wier levenloze lichaam, gewurgd, op het bed ligt. Boy staat terecht voor moord.

'Toen Boy merd binnengeleid zag William de jongen slechts een kort ogenblik van voren. Hij had mat de mensen een vollemaansgezicht noemen, een kleine mond, een dik, enigszins omhoogstaand neusje en ronde bruine ogen waarmee hij wat onmennig om zich heen keek. Hij droeg een hansop van gebleekt linnen met een gesloten kraag. Toen de rechter de zitting voor geopend had verklaard, trokken de tmee zaalmachters die aan meerskanten naast Boy zaten hem overeind en voerden hem tot voor het hekje. Hij bleef er als een standbeeld staan.

De rechter mas een kleine donkere man met behaarde handen en een plechtig stemgeluid.... Russell mas zijn naam ... Russell begon met het schetsen van de bijzondere omstandigheden rond dit proces. "Voor $u$ staat een naamloze en moordloze verdachte. Hij is niet bij machte de rechtsgang te volgen. Evenmin zal hij het vonnis dat u straks over hem zult vellen kunnen horen en begrijpen. Toch acht het openbaar ministerie het verband tussen de tenlastelegging en de hier terechtstaande verdachte zo evident dat een rechtszaak zomel onvermijdelijk als rechtvaardig is. Ondanks de ernstige handicap van de verdachte en het feit dat hij geen duidelijk omschreven identiteit bezit, kan er geen sprake van zijn dat het recht op grond van deze omstandigheden niet zijn loop zou hebben. Voor de gang van dit proces zal de verdachte in de stukken morden aangeduid met de benaming 'Onbekend'." De griffier stond nu op met een bijbel in zijn hand. Hij hield het zmarte boek met zijn gestempelde gouden letters als een dienblad voor zich uit. Een van de zaalmachters plaatste Boys rechterhand op het boek. De rechter keek de jongen aan en zei: "Zegt u mij deze moorden, ik bedoel, manneer u mij deze moorden na zou kunnen zeggen dan zou u nu het volgende zeggen." Op de gaanderij merd ingehouden gelachen. De rechter keek een ogenblik geërgerd omhoog. "Ik zmeer plechtig de maarheid te spreken en niets dan de maarheid. Zo helpe mij God almachtig." De jongen staarde de rechter roerloos aan. Boys taalloze toestand dreigde het proces nu al te laten ontsporen.' 42

Boy heeft geen schijn van kans en de eis, de doodstraf, wordt door de jury gevolgd ondanks het pleidooi van Boys raadsman dat het motief ontbreekt en dat vast is komen te staan dat Boy sterk verminderd toerekenbaar is. Williams gaat op zoek naar het echte verhaal en vindt dat, maar te laat voor Boy die in de cel zelfmoord pleegt. 